\title{
The online teaching and learning experience for pharmacoinformatics during COVID-19
}

\author{
A. Sha'aban, H. Zainal, D.A.M. Noor* \\ School of Pharmaceutical Sciences, Universiti Sains Malaysia, Malaysia
}

\section{Keywords}

Pharmacoinformatics

Online Learning

Assessment

Asynchronous Learning

Malaysia

\section{${ }^{*}$ Corresponding author dzulazri@usm.my}

\begin{abstract}
Summary: At the Universiti Sains Malaysia (USM), Pharmacoinformatics is a secondyear undergraduate Bachelor of Pharmaceutical Sciences course designed to introduce students on how to use technology to improve pharmaceutical care services. Until the outbreak of COVID-19, teaching, learning, and assessments for this course were predominantly conducted face-to-face. The unannounced arrival of the pandemic with its unprecedented uncertainties meant a drastic change in programme delivery was necessary. Social distancing and movement control orders were imposed to control the transmission of COVID-19 and hence a complete shift to online learning was required. All available tools were therefore deployed to make the transition a successful experience for both students and lecturers. The advantage of the new learning approach was that both synchronous and asynchronous learning experiences were explored. The group assignments were mostly synchronous using video conferencing applications. However, student assessments by the lecturers were predominantly asynchronous.
\end{abstract}

\section{Background and Context}

The Pharmacoinformatics course exposes students to the drug information system and the use of technology, automation, and big data in pharmacy services. The main focus of this course at School of Pharmaceutical Sciences, Universiti Sains Malaysia (USM) is to improve students skills in evaluating drug information, handling drug information requests, and using technology to disseminate health-related information. At the end of the course, the students were expected to be well acquainted with the role of pharmacists in pharmacy and health services. They were also expected, as a group, to build a pharmacy and health-related platform using digital technologies. Despite the unanticipated disruptions caused by COVID-19, the objectives of the course were achieved. Strategies and modifications adapted to meet the desired goals are worth sharing as a case study to serve as a guide for others.

\section{Educational Description}

Before the outbreak of COVID-19, assessment for USM's Bachelor of Pharmaceutical Sciences' Pharmacoinformatics course consisted of four components: continuous assessment test (10\%), a group assignment (video and website development) (35\%), an individual assignment (written) (15\%), and a final examination (40\%). During COVID-19, however, the type of assessment and marks allocation were slightly modified to continuous assessment test (10\%), group assignment 1 (video and website development) (25\%), group assignment 2 (a video presentation) (15\%), and four individual written assignments (55\%). This means that instead of having two assignments, the students were now required to undertake six assignments but without taking a final examination.

The pandemic manifested halfway through the course when almost all the coursework had finished, but no overall 
assessment had been conducted. It was no longer feasible to congregate due to social distancing and the movement control order imposed to curb the spread of the COVID-19. Therefore, all the components of the student evaluation process were significantly affected. For example, in the case of the final examination, instead of a final written exam, the students were tasked with multiple individual written assignments.

The group assignment required the students to design and physically pitch a health-related app innovation and website development. Here, the change was not in the task required but instead in the manner in which students undertook and presented the task for assessment. Previously, the group members meet physically to discuss ideas and create the website, but during the movement control order, they met online through web-conferencing software like Zoom to discuss their designs and develop the website. Formerly, a physical pitching session was organised where a representative for each group made a three to five minute presentation while being recorded by another group member, followed by a short question and answer session. Due to social distancing, a group nominee made the three to five minute video and uploaded it onto the e-learning platform. The lecturers then reviewed the videos and posted questions through the e-learning platform where the group members could access them and provide answers. The group updated/corrected their videos based on the lecturers' recommendations and then re-uploaded them for final assessment by the lecturers.

Finally, the authors conducted a survey to obtain feedback from the students on the new mechanism of learning and assessment during the pandemic outbreak (Strachota, 2006). The transition occurred midterm, thus, not all components of the course were transferred onto a virtual platform. The survey mainly asked for students' perceptions of the course content-learner interaction as well as their general satisfaction with the new transition.

\section{Outcomes and Recommendations}

Some positives and negatives were experienced with the new transition in learning and assessment. The new method promoted asynchronous learning experience as students submitted tasks and assignments onto the e-learning portal where everything is stored and can be retrieved easily by the lecturers. Also, deadlines were easily set automatically to block late submissions. This made the students more proactive and innovative. The major limitation was that the supposed group work could not be materialised physically, but it was invariably achieved online. Overall, despite the constraints, the students successfully designed the required websites and pitched their ideas wonderfully.

Sixty-seven students responded to the survey. In terms of general satisfaction, the majority of the students $(59.7 \%)$ were satisfied with the change from face-to-face to online learning. Seventy-one point one percent $(70.1 \%)$ of the students also agreed that the online method meet their learning needs. More than half (53.7\%) of the students perceived online method to be as effective as face-to-face activity method. Despite the aforementioned positive feedback, only a few $(38.8 \%)$ respondents recommend future use of the online method for this course.

With regards to the course content, nearly all (98.5\%) of the students affirmed that the learning activities in the course involve the application of problem-solving skills, which facilitated their learning. The same number (98.5\%) agreed that the assignments or projects in the course facilitated their learning. The majority of the students $(97 \%)$ agreed that the learning activities in the course required critical thinking, which facilitated their learning.

In conclusion, the faculty's experience has taught the Department that the Pharmacoinformatics course can be delivered entirely online; however, it does require some significant modifications. Although students felt burdened due to the unanticipated change in assignments, with proper planning, a transition to an online method was achievable.

\section{References}

Strachota, E. (2006). The use of survey research to measure student satisfaction in online courses. Midwest Research to Practice Conference in Adult Continuing and Community Education, University of Missouri-St Louis, United States of America 